\title{
Efficiency of gas chromatographic analysis of terpens and terpenoids of sources of aromatic substances, taking into account the polarity of the stationary phase
}

\author{
Natalia Frolova, Anatoliy Ukrainets, Oleksandra Niemirich, \\ Oksana Melnyk, Ihor Ustymenko
}

National University of Food Technologies, Kyiv, Ukraine

\section{Keywords:}

Aromatic

Terpens

Terpenoes

Chromatographic

Article history:

Received

23.01.2020

Received in revised

form 16.03.2020

Accepted

30.09 .2020

\section{Corresponding author:}

Oleksandra

Niemirich

E-mail:

niemirichav@

ukr.net

\section{DOI:}

$10.24263 / 2304-$

974X-2020-9-3-14

\section{Abstract}

Introduction. The aim of the study is to increase the efficiency of gas chromatographic analysis of terpenes and terpenoids based on the polarity of the stationary phase.

Materials and methods. It is used a model matrix №1 from a mixture of terpenes and a model matrix №2 from a mixture of terpenoids, obtained by preparative isolation in individual composition with confirmation of purity of isolation by Kovach index (IK). The analysis was performed on a chromatograph GC 8000 series, carrier gas - helium, detector - flame ionization (FID). The criteria for selecting SP GC analysis according to the Rorschneider polarity system were used.

Results and discussion. The separation of terpenoids (polar AS) into non-polar SP, the bonds inherent in polar molecules (dipole or hydrogen bonds) do not occur, so terpenoids are kept on non-polar SP SE-30 much weaker than on polar SP Carbowax 20M. The higher the values of $R_{s}$, the more efficient the gas chromatographic system of separation of terpenoids. For the column with SP Carbowax $20 \mathrm{M} \mathrm{R} \mathrm{R}_{\mathrm{s}}=$ 1.67 , for the column with SP SE-30 $\mathrm{R}_{\mathrm{s}}=1.16$.

The quantitative characterization of the universality of the studied SP with respect to the separation of terpenoids by polarity is the difference of the Kovach GIC indices. So for linalool on SP SE-30 - IR=1093, for Carbowax 20M $-I R=1582$. This means that less polar terpenoids will leave the gas chromatographic column earlier for more polar AS while ensuring complete separation of the complex mixture and the possibility of reliable and reproducible installation component composition of the prototype.

The retention time of terpenes increases with decreasing polarity of SP. Of the two experimental SP, the nonpolar SP SE-30 has a greater affinity for terpenes of the model matrix №1, which precludes obtaining on chromatograms of unresolved peaks for a critical pair of components with close Tboil. The calculated values according to the Rorschneider polarity system indicate the different polarity of the studied SP and the manifestation of characteristic intermolecular forces. When separating critical pairs of terpene hydrocarbons with close Tboil ( $\alpha$-terpinene $172.5^{\circ} \mathrm{C}$, d-limonene $173{ }^{\circ} \mathrm{C}, \alpha$-phellandrene $172{ }^{\circ} \mathrm{C}$ ) on a non-polar stationary phase $(\mathrm{SE}-30=4.40)$ the yield of components from the column is separated. peak. The use of a low-polar stationary phase (HP$5 \mathrm{~ms}, \mathrm{R}_{\mathrm{p}}>15$ ) provides a consistent output of critical pairs of terpene hydrocarbons by individual peaks in Tboil.

Conclusion. The results of the research allow us to increase the reproducibility of gas chromatographic analysis of sources of aromatic substances, as well as to choose SP, which can be interchangeable and provide a similar separation. 


\section{Introduction}

There is still no single system theory that comprehensively describes the chromatographic process. With the development of GC analysis in the world, basic theories of separation of complex mixtures of natural and synthetic origin were developed [1-7], as well as practical aspects of the implementation of theoretical developments $[8,9]$.

A multifaceted task is to conduct an effective GC analysis of sources of aromatic substances. Low reproducibility of the results of such studies, especially in interlaboratory determinations, is a problem widely discussed among chromatographers [10, 11]. Therefore, a significant part of scientific works is devoted to the search for theoretical and practical ways of developing the gas chromatographic method to increase the probability of the obtained results of the analysis of sources of aromatic substances, reducing their differences [11-13].

Scientific publications on GC analysis of sources of aromatic substances are concentrated in specialized journals $[14,15]$. Food flavor studies are less represented. This analysis is complicated by the instability of the component composition of sources of aromatic substances in food, which is influenced by the location and seasonality of raw materials, varietal affiliation, method of processing [16-18].

The reason for the differences in the results is not only due to insufficient elaboration of the theory of intermolecular interactions between terpenes, terpenoids in terms of their contact with SP of different polarity $[17,19]$. The analysis is complicated by the presence in natural sources of the aroma of substances of different homologous series, including terpenes, oxygen-containing components, which are separated in a narrow range of boiling points $\left(\mathrm{T}_{\text {boil }}\right)$. This causes overlapping and masking of peaks on the chromatograms of different sources of AS. [11, 12, 20].

Indeed, in GC analysis of sources of aromatic substances, the balanced distribution of components in the column is established over time. Therefore, the concentration zones during the migration of components along the column can expand, "blur". This complicates the accurate determination of the qualitative composition and quantitative content of the components of aromatic substances in food and requires the correct choice not only of the modes of GC analysis, but also SP analytical column.

It is known that the correct choice of the stationary phase (SP) of the analytical column [21] largely depends on the efficiency of GC analysis.

The methodology of SP evaluation according to different selection criteria is considered in many classical works [22-25], in modern publications [1, 21, 26]. In turn, M. Wigderhaus proposed to divide SP into 7 main groups based on the relationships between the constants of the Rorschneider system and the McReynolds scale [27] with the participation of the chromatographic polarity $\mathrm{Pp},[1,16,22,28]$.

Rorschneider [29] proposed a formula that calculates the relative chromatographic polarity of PS - Ps, \% and compiled a system of polarity of SP, in particular: nonpolar (Ps = $0-5 \%)$, weakly polar $(\mathrm{Ps}=5-15 \%)$, medium polar $=15-35 \%)$, strongly polar $(\mathrm{Ps}=50-$ $100 \%)$. McReynolds proposed the SP selectivity scale as a development of the Rorschneider system [30]. According to this scale, the selectivity of SP is estimated as the difference between the content indices of Kovach GIC 10 standard substances with close Tboil. In addition to benzene (X), butanol (B), methyl propyl ketone (Z), nitropropane (U), pyridine (S) proposed by Rorschneider [29, 30], 2-methyl-pentanol-2 (H), 1-iodobutane (I), octin-2 (K), 1,4-dioxane (L), cis-hydrindane (M). The higher the values of the McReynolds constants, the greater the selectivity of SP to the components of the mixture with close to boiling point $\mathrm{T}$, the longer they will be in contact with SP. Components with low values of McReynolds constants will come out of the column first. 
At the same time, it should be noted that the criteria for the selection of effective SP developed by scientists so far are being criticized and work is underway to find new approaches that can be reproduced in different laboratories [10, 31].

The relevance of such research is based not only on purely scientific or cognitive interest. We are talking about the requirements of the rapidly growing worldwide industry of food flavors and synthetic flavors [32, 33].

The study aims to study the effectiveness of gas chromatographic analysis of terpenes and terpenoids taking into account the polarity of the stationary phase and the formation of criteria for selecting SP for the analysis of aroma sources according to the Rorschneider polarity system.

\section{Materials and methods}

\section{Materials}

Two model matrices are used in the work.

Model matrix №1. The model matrix №1 included 7 terpene hydrocarbons (terpenes) of individual composition isolated by laboratory preparative chromatography. These are: $\alpha$ pinene, camphene, $\beta$-pinene, $\beta$-myrcene, $\beta$-phellandrene, $\alpha$-terpinene and d-limonene.

In the Table 1 information on the characteristics of the model matrix №1 is collected.

Model matrix №2. The model matrix №2 combines oxygen-containing components (terpenoids) of different chemical classes of aliphatic and cyclic nature, in particular alcohols (aliphatic 1-linalool, monocyclic $\alpha$-terpineol), aldehyde (citral), ketone (carvone), ester of terpene and terpene acids (geranyl acetat).

In the Table 2 information on the components of the model matrix №2 is collected.

\section{Research methods}

Preparative chromatography for laboratory production of terpenes, terpenoids of individual composition from cumin essential oil

Obtaining terpene hydrocarbons was controlled distillation of cumin essential oils into fractions at stage 1 in the adiabatic mode according to technological maps [34] with their subsequent concentration in "narrow fractions" with a component content $65-75 \%$ of the mass. Preparative chromatography (stage 2) was used to disperse the "narrow fractions" into terpenes and terpenoids. An effective nozzle of the preparative column with a gradient application of portions of the stationary phase PEG6000 on individual sections of the solid carrier (Chromosorb A) was developed. Table 3 shows the sequence of application of SP on TN.

Modes of preparative isolation of terpenes, terpenoids of individual composition: preparative chromatograph "Chromium 31A". Column dimensions: steel spiral tube 500×10 mm (inner diameter). Solid carrier: Chromosorb A (30/40 mesh). Smobile phase Polyethylene glycol adipinate - PEG-6000. Application of NF on TH - gradient Temperature: injector $(180-250){ }^{\circ} \mathrm{C}$, column thermostat $(145-210){ }^{\circ} \mathrm{C}$ (with clarification for each fraction). Carrier gas: nitrogen $1.33 \mathrm{~m}^{3} / \mathrm{h}$. Column load: $0.6 \pm 0.1$ to $1 \mathrm{~g}$ (for repeated cycles). Detector: $170 \mathrm{~mA}$ catharometer [35]. 
Table 1

Generalized characteristics of the model matrix № 1

\begin{tabular}{|l|c|c|c|}
\hline Component matrix & Method of obtaining & $\mathrm{Ps}^{* *}$ & $\mathrm{~T}_{\text {boil }},{ }^{\circ} \mathrm{C}$ \\
\hline 1. $\beta$-myrcene & $\mathrm{PS} *$ mass spectrum & +4 & $167 \pm 2,0$ \\
\hline 2. $\beta$-phellandrene & $\mathrm{PS} *$, Kovach index & +3 & $172 \pm 2,0$ \\
\hline 3. d-limonene & $\mathrm{PS} *$ Kovach index & +3 & $172 \pm 2,0$ \\
\hline 4. Kamfen & $\mathrm{PS} *$, Kovach index & +2 & $159 \pm 2,0$ \\
\hline 5. $\beta$-pinene & $\mathrm{PS} *$ mass spectrum, & +2 & $160 \pm 2,0$ \\
\hline 6. $\alpha$-pinene & $\mathrm{PS} *$ Kovach index & +1 & $153 \pm 2,0$ \\
\hline 7. $\alpha$-terpinene & $\mathrm{PS} *$, Kovach index & +1 & 173 \\
\hline
\end{tabular}

* PS - preparative selection, ** polarity

Table 2

Generalized characteristics of the model matrix № 2

\begin{tabular}{|l|l|l|c|l|}
\hline \multicolumn{2}{|c|}{ Component } & $\begin{array}{c}\text { Method of obtaining, } \\
\text { identification }\end{array}$ & $\begin{array}{c}\text { Tboil } \\
{ }^{\circ} \text { C }\end{array}$ & Ps** \\
\hline 1 & citral & PS *, Kovach index & $176,0 \pm 2,0$ & +3 \\
\hline 2 & d- carvone & PS *, optical activity & $230,0 \pm 2,0$ & +3 \\
\hline 3 & 1-linalool & PS *, optical activity & $198,0 \pm 2,0$ & +4 \\
\hline 4 & geranyl acetate & PS *, mass spectrum, & $199,0 \pm 2,0$ & +3 \\
\hline 5 & ó-terpineol & PS *, mass spectrum, & $224,0 \pm 2,0$ & +3 \\
\hline
\end{tabular}

* PS - preparative selection, ** polarity

Table 3

Sequence of application of SP on TN preparative column

\begin{tabular}{|c|l|l|l|l|}
\hline $\begin{array}{c}\text { Number } \\
\text { section }\end{array}$ & Particle size, mm & $\begin{array}{c}\text { Content, } \\
\text { \% mass }\end{array}$ & $\begin{array}{c}\text { Column filling } \\
\text { volume, } \mathbf{g}\end{array}$ & Weight, g \\
\hline 1 & $2,0-3,0$ & 15 & 97 & 48,00 \\
\hline 2 & $1,0-2,0$ & 25 & 148 & 70,87 \\
\hline 3 & $0,56-1,0$ & 60 & 240 & 130,00 \\
\hline
\end{tabular}

\section{Determination of the Kovach index}

Kovach index is calculated according the method based on the recorded gas chromatographic characteristics [36].

Identification of conformity of substances of preparative allocation to a chemical class of terpenes, terpenoids

Identification was performed according to the Kovach index [36].

Identification of conformity of substances of preparative selection to the chemical class of terpenes, terpenoids by mass spectra

The LECO/Fiehn Metabolomics Library and the 2011 Pfleger-Maurer-Weber Mass Spectrum Database (approximately 8,500 compounds) were used for identification. The results were processed by the data processing system of the MX-E model. The identity of both mass spectra $\geq 92 \%$ confirms the identity of the component with a probability of more than $92 \%$. 


\section{Modes of GC analysis of test samples}

The analysis was performed on a GC 8000 series chromatograph, carrier gas - helium, costs: through the column $-1 \mathrm{~cm}^{3} / \mathrm{min}$, through the column $-1.2 \mathrm{~cm}^{3} / \mathrm{min}$, for discharge from the injector $-100 \mathrm{~cm}^{3} / \mathrm{min}$, programming the temperature of the column thermostat: initial $-100{ }^{\circ} \mathrm{C}$, final $-180{ }^{\circ} \mathrm{C}$; programming speed $-8{ }^{\circ} \mathrm{C} / \mathrm{min}$; sample volume $0.2 \mu$. Detector - flame ionization (FID).

\section{Removal of chromatographic profiles}

The areas of the chromatographic peaks of the As model matrix were calculated by the electronic automated system CAA-006 by the method of internal normalization with statistical processing of data from parallel experiments (5 repetitions). The variance of the deviation S2 was calculated, the reliable interval of probable values $\pm \sigma$ relative to the critical Student's criterion $\mathrm{Tcr}=4.42$.

Establishing the level of the polarity of the components of the model matrix

Table 4 show systematization of AS on the manifestation of hydrogen bonds the sequence of application of SP on TN.

\section{Systematization of AS on the manifestation of hydrogen bonds the sequence}

Table 4 of application of SP on TN

\begin{tabular}{|c|c|c|}
\hline Class characteristics & Aromatic substances & Polarity \\
\hline \multirow{2}{*}{$\begin{array}{l}\text { Class 1. Repeated manifestation of } \\
\text { hydrogen bonds }\end{array}$} & Polyphenols & \multirow[b]{2}{*}{+5} \\
\hline & Hydroxy acids & \\
\hline \multirow{2}{*}{$\begin{array}{l}\text { Class II. The presence of both a } \\
\text { donor atom }(\mathrm{O}, \mathrm{N}) \text { and an active } \\
\text { hydrogen atom }\end{array}$} & $\begin{array}{l}\text { Alcohols, geraniol, nerol, citronellol, } \\
\text { farnesidol, terpineol, menthol, borneol }\end{array}$ & \multirow[t]{2}{*}{+4} \\
\hline & Phenols: eugenol & \\
\hline \multirow{3}{*}{$\begin{array}{l}\text { Class III. The presence of a donor } \\
\text { atom, the absence of an active } \\
\text { hydrogen atom }\end{array}$} & Ethers & \multirow{3}{*}{+3} \\
\hline & $\begin{array}{l}\text { Citral, gerenial, citronenal, carvone, } \\
\text { camphor }\end{array}$ & \\
\hline & Esters - geranyl acetate, linalyl acetate & \\
\hline \multirow{2}{*}{$\begin{array}{l}\text { Class IV. The presence of an } \\
\text { active hydrogen atom, the absence } \\
\text { of a donor atom. }\end{array}$} & $\begin{array}{l}\text { Unsaturated hydrocarbons - limonene, } \\
\alpha, \beta \text {-pinene, camphene }\end{array}$ & \multirow{2}{*}{+2} \\
\hline & $\begin{array}{l}\text { Terpene, sesquiterpene, aromatic } \\
\text { hydrocarbons }\end{array}$ & \\
\hline $\begin{array}{l}\text { Class V. Do not form hydrogen } \\
\text { bonds }\end{array}$ & Saturated hydrocarbons & +1 \\
\hline
\end{tabular}

The systematization of AS on the manifestation of hydrogen bonds [36-38], the ability to form a dipole, and orientation interactions (Table 5), [30]. 
Systematization of AS by the ability to form dipole and orientation interactions

\begin{tabular}{|l|c|c|}
\hline Class characteristics & Aromatic substances & Polarity \\
\hline $\begin{array}{l}\text { Molecules without permanent dipoles or } \\
\text { functional groups }\end{array}$ & - & +1 \\
\hline $\begin{array}{l}\text { Molecules with almost imperceptible } \\
\text { dipoles }\end{array}$ & Terpenes, sesquiterpenes & +2 \\
\hline $\begin{array}{l}\text { Molecules with constant dipoles, } \\
\text { electronegative atoms, but without a } \\
\text { single active hydrogen atom }\end{array}$ & $\begin{array}{c}\text { Aromatic alcohols, aldehydes, } \\
\text { terpene ketones, esters, lactones } \\
\text { and acids }\end{array}$ & +3 \\
\hline $\begin{array}{l}\text { Molecules with strong dipole moment, } \\
\text { free electron pairs }\end{array}$ & $\begin{array}{c}\text { Aliphatic, terpene and } \\
\text { sesquiterpene alcohols, phenols } \\
\text { and phenol esters }\end{array}$ & +4 \\
\hline $\begin{array}{l}\text { Molecules with a strong dipole moment } \\
\text { and a three-dimensional arrangement of } \\
\text { hydrogen bonds }\end{array}$ & - & +5 \\
\hline
\end{tabular}

Establishing the polarity of SP effective against AS sources of aroma by the values of Rorschneider constants

Reference tables with values of SP polarity according to the Rorschneider system were used [27] and the selected SP are effective against AS sources of aroma.

According to the Rorschneider polarity system, the value of the relative polarity $\mathrm{P}_{\mathrm{P}}$ is calculated by the following formula

$$
P_{p}=\frac{(\mathrm{x}+\mathrm{y}+z+\mathrm{u}+\mathrm{s})}{5 \cdot 10}
$$

$\mathrm{x}, \mathrm{y}, \mathrm{z}, \mathrm{u}, \mathrm{s}$ are Rorschneider constants

In formula 1, the Rorschneider constant $\mathrm{x}$ characterizes mainly inductive interactions. Rorschneider's constant $y$ - is mainly donor-acceptor interactions of terpene alcohols.

The Rorschneider constant $\mathrm{z}$ is responsible for dipole-dipole (orientation) interactions of ketones, aldehydes, ethers, esters. The Rorschneider constant $u$ is mainly related to the hydrogen bond of cycloaliphatic compounds. The Rorschneider constant s is related to orientational interactions. These are AR complex compounds, including oxygen-containing substances, macrocyclic lactones, and oxylactones.

According to Rorschneider, nonpolar SP include those for which $\mathrm{P}_{\mathrm{p}}=0-5$, weakly polar $\mathrm{P}_{\mathrm{p}}=5-15$, medium polar $-\mathrm{P}_{\mathrm{p}}=15-35$, strongly polar $-\mathrm{P}_{\mathrm{p}}=50-100$.

\section{Determination of characteristic indicators of GC analysis [27].}

The degree of separation of RS, as the ability of the GC column to separate the "critical pair" of components (d-carvone and citral). The following formula was used:

$$
R_{s}=\frac{2 \cdot\left(t_{R 2}-t_{R 1}\right)}{w 1+w 2}
$$

where: $t_{R 2}, t_{R 1}$ - retention time, min, w1, w2 - peak width of d-carvone and citral along the zero line, $\mathrm{mm}$.

The selectivity of the separation $\alpha$ was calculated by the following formula: 


$$
\alpha=\frac{t_{R 1}}{t_{R 1}}
$$

where: $t_{R 2}, t_{R 1}$ - retention time of the first and last components at the exit of the column. In practice, GC analysis is considered satisfactory value of $\alpha$ within $0.8-1.0$

The extraction coefficient $k^{\prime}$ was found as the ratio of the corrected retention time $\mathrm{t}^{\prime} \mathrm{R}$ - to the "dead time" $t_{0}$ :

$$
k^{\prime}=\frac{t_{R}}{t_{R 0}}=\frac{t_{R 2}-t_{0}}{t_{0}}
$$

\section{Results and discussion}

Investigation of the efficiency of gas chromatographic analysis of terpenoids taking into account the polarity of the stationary phase

Table 6 shows the results of the study of the effectiveness of the influence of intermolecular interactions of terpenoids of the model matrix № 2 and SP of different polarities. The studies calculated the logarithm of the relative retention time of lgt' $\mathrm{R}$ on chromatograms obtained on capillary columns with non-polar SP SE-30 and polar SP Carbowax 20M.

Signals of terpenoid content on SP of different polarity

\begin{tabular}{|c|c|c|c|c|c|c|}
\hline \multirow[t]{3}{*}{ Terpenoids } & \multicolumn{6}{|c|}{ Stationary phases } \\
\hline & \multicolumn{3}{|c|}{ SE-30 (a) } & \multicolumn{3}{|c|}{ Carbowax 20M ( b) } \\
\hline & $\operatorname{lgt}_{R}^{\prime}$ & & $\mathrm{IK}_{\mathrm{a}}^{*}$ & $\operatorname{lgt}_{R}^{\prime}$ & & $\mathrm{IK}_{\mathrm{B}}$ \\
\hline Linalool & 2,32 & & 1093 & 2,81 & & 1582 \\
\hline$\alpha$-terpineol & 2,72 & & 1230 & 2,92 & & 1591 \\
\hline Citral & 2,87 & \multirow[t]{2}{*}{$\mathrm{Rs}=1,16$} & 1272 & 3,42 & \multirow[t]{2}{*}{ Rs $=1,67$} & 1767 \\
\hline d-carvone & 2,83 & & 1264 & 3,01 & & 1725 \\
\hline Linalyl acetate & \multicolumn{2}{|l|}{2,92} & 1290 & \multicolumn{2}{|l|}{3,47} & 1783 \\
\hline Geranyl acetate & \multicolumn{2}{|l|}{3,08} & 1308 & \multicolumn{2}{|l|}{3,64} & 1848 \\
\hline
\end{tabular}

Table 6

* Estimated values of Kovach indices (IK).

Based on the data in Table 6, the following provisions should be discussed.

Terpenoids with different functional groups belong to polar compounds, so they last longer on polar SP than on non-polar SP.

Terpene alcohols have sp3-hybridization of the oxygen atom of the hydroxyl group [27]. This determines their electron-donor properties. The polar bond $(\mathrm{C}-\mathrm{O})$ and $(\mathrm{O}-\mathrm{H})$ are capable of forming hydrogen bonds. Unlike terpene alcohols, aldehyde and ketone molecules do not have mobile hydrogen atoms that are bound to oxygen atoms. As a result, the aldehyde citral and ketone d-carvone are less reactive than alcohols but show orientational interactions.

This affects the fact that in polar SP terpene alcohols are obtained earlier than aldehydes.

Geranyl acetate ester has the longest retention time among the terpenoids studied and shows better separation into polar SP. In such interactions, the orientation forces are shown mainly. Modification of nonpolar SP by strongly polar AS can also occur with the formation of instantaneous dipole moments of induction interactions. 
The difference in relative polarity in the group of terpenoids is also explained by the difference in their structural structure. Thus, the most polar of the studied terpenoids are geranyl acetate (Table 2). It has the longest retention time on the column with SP Carbowax 20M.

The interaction of SP SE-30 with terpenoids is determined mainly by dispersion forces. Therefore, terpene alcohols on a non-polar column have a significantly shorter retention time (lgt'R) compared to SP Carbowax20M (linalool 2.32, 2.81).

Indicative, when comparing gas chromatographic columns, is the value of Rs. Under the condition Rs $<1$, the peaks overlap. Accurate determination of parameters, especially quantitative ones, becomes impossible [23]. Therefore, the higher the values of Rs, the more efficient the gas chromatographic system of separation of terpenoids.

From the Table 6 we observe the difference of Rs values for the studied columns. For the column with SP Carbowax 20M Rs $=1.67$, for the column with SP SE-30 Rs $=1.16$.

The difference of Kovach $\triangle \mathrm{IK}$ indices can also be considered as a quantitative characteristic of the universality of the studied SP $(a, c)$ in terms of the separation of terpenoids by polarity.

$$
\Delta \mathrm{IK}=\left|\mathrm{IK}_{\mathrm{B}}-\mathrm{IK}_{\mathrm{a}}\right|
$$

A higher value for the $\Delta \mathrm{IK}$ of the test substance on one of the compared SP indicates a higher polarity of this SP, and this As behaves on this SP as a more polar substance.

According to the obtained data (Table 6) for linalool on SP SE-30, IR $=1093$, for Carbowax20M, IR $=1582$. This means that of the compared SP polarity Carbowax $20 \mathrm{M}$ is much greater than in SP SE-30.

Studies have shown that less polar terpenoids will leave the gas chromatography column earlier than more polar AS. Therefore, Carbowax 20M shows greater polarity than SP SE30 .

Investigation of the efficiency of gas chromatographic analysis of terpenes and taking into account the polarity of the stationary phase

Studies of the separation of the model matrix, 2, which consisted of terpenes on columns with nonpolar SP SE-30 and polar SP Carbowax 20M (Figure 1).

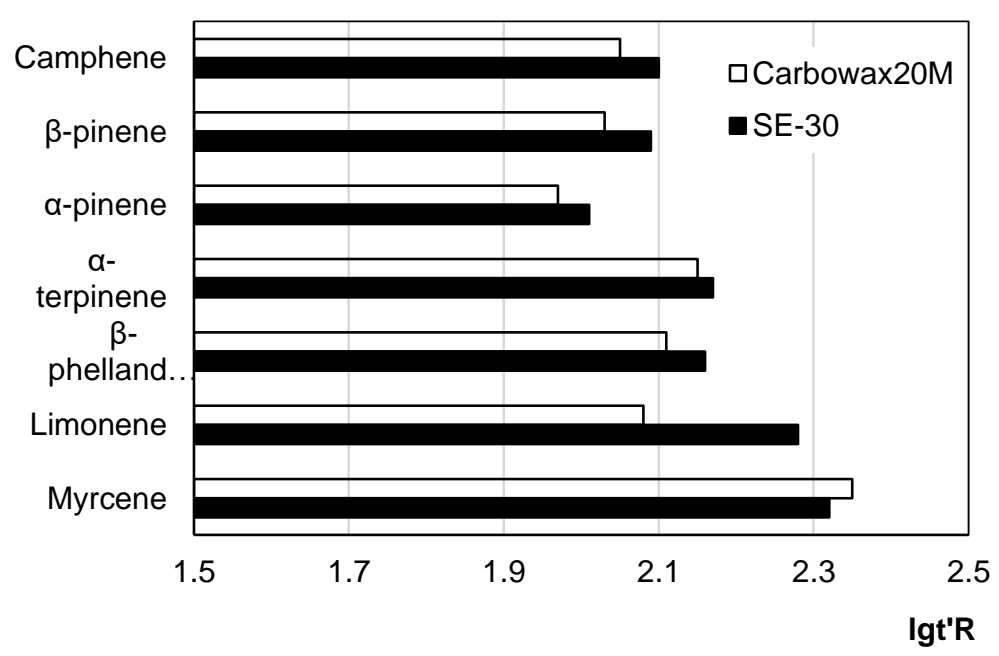

Figure 1. lgt'R AR terpenes obtained on SP of different polarity 
Chromatograms were calculated relative to the logarithm of the corrected retention time - lgt'R components of the model matrix taking into account the time of methane yield $\left(\mathrm{t}_{\mathrm{m}}=44 \mathrm{~s}\right)$.

Based on the data in Figure 1, the following provisions should be discussed

The results show noticeable differences in the interaction of nonpolar terpenes with SP of the corresponding and opposite polarity. The diagram shows that the components with a cyclic structure (camphene, $\alpha$ - and $\beta$-pinene) have a lower retention time than substances of aliphatic structure (myrcene) on both SP. The increase in the number of cycles in the structure of the molecule reduces the retention time of the components. The presence of double bonds increases the polarity of the components. Thus, monocyclic $\alpha$-terpinene with two double bonds in the middle of the ring (Figure 1) interacts equally with SP of different polarity. The appreciable difference of the maintenance of d-limonene on SP of various polarity is explained by the existence of double communication outside of a ring. In our opinion, limonene has the strongest bond with SP Carbowax 20M due to the proximity of the natural chemical structure. Myrzen with three double bonds is the most polar of the other terpenes. This explains its longer retention time in polar SP. In addition, there is a partial deformation of SP Carbowax 20M under the influence of the induced dipole moment.

It should be noted that the double bond in the middle of the $\alpha$-pinene cycle affects the reduction of retention time on both SP in comparison with $\beta$-pinene, in which the double bond is in the side chain of the cycle. Also, $\beta$-myrcene, $d$-limonene, camphene, $\beta$-pinene have a pair of $\pi$-bonds in the extreme chain and are fundamentally more polar than terpenes with double bonds in the middle of the ring $-\alpha$-pinene, $\beta$-felladndren, $\alpha$ - the patient.

Therefore, the retention time of terpenes increases with decreasing polarity of SP. Of the two experimental SP, nonpolar SP SE-30 has a greater affinity with terpenes of the model matrix №1, extends the ability to avoid undivided peaks for components with close $\mathrm{T}_{\text {boil }}$.

Selection of effective SP GC analysis of aroma sources according to the Rorschneider system taking into account the chromatographic polarity of $\mathrm{P}_{\mathrm{P}}$.

The study was performed with the participation of two nonpolar SP - SP -SE-30 and SP-HP-5ms.

The values of $P_{P}$ for the studied SP were calculated by the difference of the Kovach indices (IK) according to the following formula:

$$
P_{p}=\frac{\Delta I K_{x}+\Delta I K_{y}+\Delta I K_{z}+\Delta I K_{u}+\Delta I K_{S}}{5 \cdot 10}
$$

where: $\Delta \mathrm{I} K \mathrm{x}$ characterizes mainly induction interactions and shows the degree of increase in terpene retention time.

$\Delta \mathrm{IKy}$ - mainly donor-acceptor interactions of terpene alcohols. ethers.

$\Delta \mathrm{IKz}$ is responsible for dipole-dipole (orientation) interactions of ketones, aldehydes,

$\Delta \mathrm{IKu}$ is mainly associated with the hydrogen bond of cycloaliphatic compounds.

$\Delta \mathrm{IKs}$ is associated with the orientational interactions of oxygen-containing substances, macrocyclic lactones and oxylactones.

The results of the determination of IK terpenes on nonpolar SP-SE-30 and SP -HP-5ms are shown in the Table. 8 . 
Values of hydrocarbon (IK) content of terpenes for the studied SP

Table 8

\begin{tabular}{|l|l|l|l|l|l|l|}
\hline \multirow{2}{*}{ Terpenes } & \multicolumn{3}{|l|}{$\mathrm{SP}-\mathrm{SE}-30$} & \multicolumn{3}{l|}{$\mathrm{SP}-\mathrm{HP}-5 \mathrm{~ms}$} \\
\cline { 2 - 7 } & $\operatorname{lgV}_{\mathrm{R}}$ & $\operatorname{lgt}_{\mathrm{R}}$ & $\mathrm{IK}$ & $\operatorname{lgV}_{\mathrm{R}}^{\prime}$ & $\operatorname{lgt}_{\mathrm{R}}$ & $\mathrm{IK}$ \\
\hline$\alpha$-pinene & 2,00 & 2,00 & 942 & 2,00 & 2,00 & 1039 \\
\hline camphene & 1,20 & 2,07 & 951 & 1,28 & 2,11 & 1083 \\
\hline$\beta$-pinene & 1,48 & 2,17 & 968 & 1,58 & 2,19 & 1124 \\
\hline$\alpha$-terpinene & 1,89 & 2,24 & 1010 & 2,09 & 2,33 & 1190 \\
\hline d-limonene & 2,04 & 2,31 & 1021 & 2,29 & 2,36 & 1206 \\
\hline$\beta$-phellandrene & 2,24 & 2,36 & 1025 & 2,16 & 2,39 & 1216 \\
\hline
\end{tabular}

In the Table 7 there is shown the values of the Rorschneider constants and calculates the polarity of the studied SP.

Polarity $P_{P}$ of the studied SP according to the Rorschneider system

Table 7

\begin{tabular}{|c|c|c|c|c|c|c|c|}
\hline \multirow[b]{2}{*}{ Names SP } & \multicolumn{5}{|c|}{ Rorschneider's constants } & \multirow[b]{2}{*}{$\sum \Delta \mathrm{IK}_{1-5}$} & \multirow[b]{2}{*}{$P_{p}$} \\
\hline & $\begin{array}{c}\Delta \mathrm{IK}_{1} \\
(x)\end{array}$ & $\begin{array}{l}\Delta \mathrm{IK}_{2} \\
(\mathrm{y})\end{array}$ & $\begin{array}{l}\Delta \mathrm{IK}_{3} \\
(\mathrm{z})\end{array}$ & $\begin{array}{c}\Delta \mathrm{IK}_{4} \\
(u)\end{array}$ & $\begin{array}{c}\Delta \mathrm{IK}_{5} \\
(s)\end{array}$ & & \\
\hline SE-30 & 16 & 53 & 44 & 64 & 41 & 220 & 4,40 \\
\hline HP-5ms & 52 & 172 & 95 & 198 & 147 & 734 & 15,36 \\
\hline Carbowax 20M & 322 & 536 & 368 & 572 & 510 & 2308 & 46,15 \\
\hline
\end{tabular}

The calculated values Pp indicate the different polarity of the studied SP and the manifestation of characteristic intermolecular forces. Terpene hydrocarbons are more characterized by dispersion interactions $(90-95 \%)$ and instantaneous induction interactions (5 $1 / 410 \%)$.

The obtained data allow to select SP which can be interchangeable, ie to provide similar division.

In Figure 2 there is shown the chromatograms of the model matrix № 1 obtained on capillary columns with nonpolar SP SE-30 $\left(\mathrm{P}_{\mathrm{p}}=4.40\right)$ and weakly polar SP HP-5ms $\left(\mathrm{P}_{\mathrm{p}}=\right.$ 15.36). The obtained chromatograms revealed differences in the separation of terpenes of the model matrix into SP of different polarity.

Analysis of the chromatograms showed that the column with SP SE-30 showed incomplete separation of critical pairs of terpenes (groups 1 and 2). The calculated molecular statistics for the critical pair of camphene and $\beta$-pinene (1) on SP SE-30 have a selectivity coefficient $\alpha 1=0.67$; extraction factor $k_{1}^{\prime}=1.22$; separation criterion $R_{S 1}=0.91$. For the pair $\beta$-phellandrene and $\alpha$-terpinene (2): $\alpha 2=0.78 ; \mathrm{k}_{2}^{\prime}=1.26 ; R_{S 2}=0.94$. On the column HP-5ms for pair $1: \alpha 1=1.32 ; \mathrm{k}_{1}^{\prime}=3.12 ; R_{S 1}=1.56$. For pair $2: \alpha 2=2.75 ; \mathrm{k}_{2}^{\prime}=3.86 ; R_{S 2}=2.04$.

In addition, the column with SP HP-5ms shows a prolonged retention time of terpenes. The camphene is the most polar component of the matrix and lasts longer on SP HP-5ms than on SP SE-30.

Such data allowed to propose a working column with SP HP-5ms for GC analysis of terpene hydrocarbons (Table 8). 


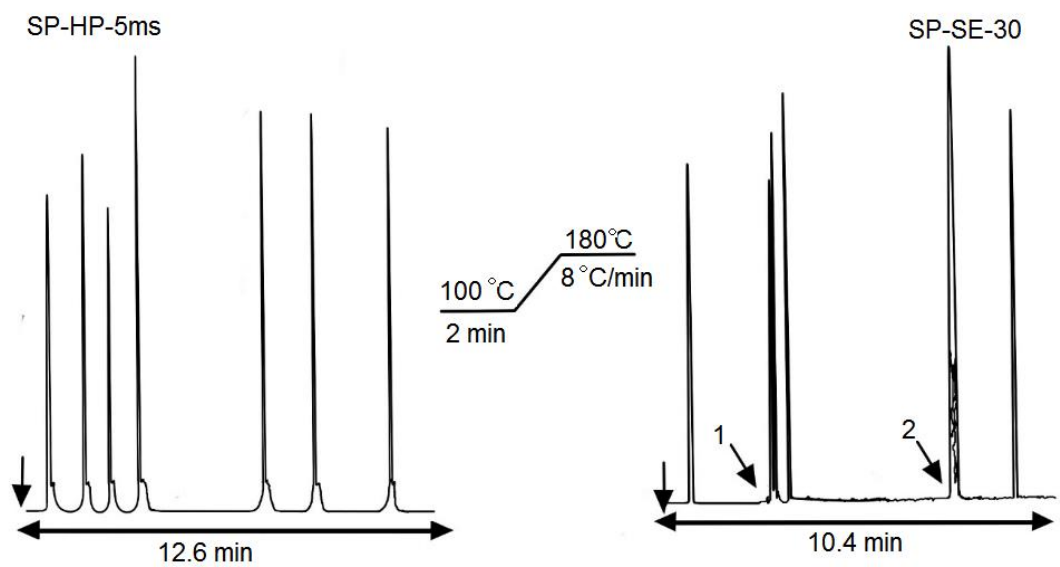

Figure 2. Chromatograms of the model matrix obtained on capillary columns with SP - SP SE-30 and HP-5ms

Characteristics of the capillary column HP-5ms

Table 8

\begin{tabular}{|l|l|}
\hline Indicator & Value \\
\hline Column material & quartz \\
\hline Stationary phase & HP-5ms, (DB-5 ms) \\
\hline Operating temperature, ${ }^{\circ} \mathrm{C}$ & 320 \\
\hline Geometric dimensions (d/L) & $30 \mathrm{~m} / 0,25 \mathrm{Mm}$ \\
\hline The thickness of the SP film, $\mu \mathrm{m}^{\mathrm{m}} \mathrm{10}$ \\
\hline Rorschneider polarity & 15,36 \\
\hline Number of theoretical plates & $21162-22071$ \\
\hline Height of the theoretical plate (VETT), mm & $0,7-0,94$ \\
\hline Column selectivity for b-pinene and $\beta$-terpinene & 1,$42 ; 1,8$. \\
\hline Calculated extraction factor & $k^{\prime}=1,32-1,64$ \\
\hline
\end{tabular}

Note that due to the close Tboil critical pairs of terpene hydrocarbons with the imposition of peaks, there is a need to correct the conditions of gas chromatographic analysis.

\section{Conclusions}

Studies have shown the need to take into account the polarity of $\mathrm{P}_{\mathrm{P}} \mathrm{SP}$ column when GC analysis of terpenes and terpenoids of the experimental mixture of aromatic substances. This indicator is directly related to the energy of intermolecular interactions of AS with SP, and affects their retention time in the column, Kovach index, value Rs as an indicator of the purity of the separation. 
It was found that when separating terpenoids (polar AS) into nonpolar SP bonds inherent in polar molecules (dipole or hydrogen bonds) do not occur, so terpenoids are retained on nonpolar SP SE-30 much weaker than on polar SP Carbowax20M . Under such conditions, less polar terpenoids will leave the gas chromatographic column earlier than more polar AS ones.

The retention time of terpenes increases with decreasing polarity of SP. Of the two experimental SP, nonpolar SP SE-30 has a greater affinity with terpenes of the model matrix №1, excludes obtaining on chromatograms of unresolved peaks for components with close Tboil.

Therefore, taking into account the polarity of the stationary phase, the efficiency of gas chromatographic analysis of terpenes and terpenoids increases due to the maximum exclusion of overlap and masking of peaks on chromatograms, obtaining the most separated front of the mixture components and accurate determination of qualitative composition and quantitative content of components

The results of research allow us to increase the reproducibility of gas chromatographic analysis, as well as to choose stationary phases that can be interchangeable and provide a similar separation, which will reduce the cost of the laboratory budget.

\section{References}

1. Smith I. (2013), Chromatography, Elsevier.

2. Špánik I., Andrea M. (2018), Recent applications of gas chromatography with high-resolution mass spectrometry, Journal of Separation Science, 41(1), pp. 163-179.

3. Gruber B., Frank D., Pat S. (2020), Capillary gas chromatography-mass spectrometry: Current trends and perspectives, TrAC Trends in Analytical Chemistry, pp. 115-475.

4. Al-Rubaye Abeer Fauzi, Imad Hadi Hameed, Mohanad Jawad Kadhim (2017), A review: Uses of gas chromatography-Mass Spectrometry (GC-MS) technique for analysis of bioactive natural compounds of some plants, International Journal of Toxicological and Pharmacological Research, 9(1), pp. 81-85.

5. Poole Colin F. (2005), Evaluation of the Solvation Parameter Model as a Quantitative StructureRetention Relationship Model for Gas and Liquid Chromatography, Journal of Chromatography, A(2020), pp. 461308.

6. Ihara H. et al. (2005), Encyclopedia of Chromatography, New York.

7. Uclés S., et al. (2017), Shifting the paradigm in gas chromatography mass spectrometry pesticide analysis using high resolution accurate mass spectrometry, Journal of Chromatography, A1501, pp. 107-116.

8. Peng, Jianlin, et al. (2016), High-resolution separation performance of poly (caprolactone) diol for challenging isomers of xylenes, phenols and anilines by capillary gas chromatography, Journal of Chromatography, A 1466, pp. 148-154.

9. Lee, Hyeok-Won, et al. (2019), Development of novel on-line capillary gas chromatographybased analysis method for volatile organic compounds produced by aerobic fermentation, Journal of bioscience and bioengineering, 127(1), pp. 121-127.

10. Jepshtejn N.A., Emshanova S.V. (2008), O trebovanijah k prigodnosti hromatograficheskoj sistemy pri kontrole kachestva lekarstvennyh substancij i preparatov metodom, VJeZhH, Himikofarmacevticheskij zhurnal, 11, pp. 34-0.

11. Niu Yunwei, et al. (2019), Characterization of ester odorants of apple juice by gas chromatography-olfactometry, quantitative measurements, odour threshold, aroma intensity and electronic nose, Food Research International, 120, pp. 92-101

12. Chen Wentian et al. (2017), Characterizing red radish pigment off-odor and aroma-active compounds by sensory evaluation, gas chromatography-mass spectrometry/olfactometry and partial least square regression, Food and Bioprocess Technology, 10(7), pp. 1337-1353. 
13. Mazurek B., M. Chmiel, Górecka B. (2017), Fatty Acids Analysis Using Gas ChromatographyMass Spectrometer Detector (GC/MSD)-Method Validation Based on Berry Seed Extract Samples, Food Analytical Methods, 10(8), pp. 2868-2880.

14. Fox A. et al. (ed.). (2013), Analytical microbiology methods: chromatography and mass spectrometry, Springer Science \& Business Media.

15. Charalambous G. (2002), Instrumental analysis of foods, Academic Press, New York.

16. Özek T. (2012), Isolation of natural products by preparative gas chromatography, Natural Products Isolation Humana Press, pp. 275-300

17. Doty Richard L. (2015), Handbook of Olfaction and Gustation, Wiley \& Sons.

18. Arutjunov Ju.I., Kudrjashov S.Ju., Onuchak L.A. (2005), Gazohromatograficheskij analiz smesej, soderzhashhih neizvestnye komponenty, Vestnik SamGU. Estestvenno-nauchnaja serija, 5, pp. $137-162$.

19. Jashin Ja.I. (1986), Fiziko-himicheskie osnovy hromatograficheskogo razdelenija, Moscow.

20. Smith, Charles G. (2020), Handbook of Chromatography: Volume II: Polymers, CRC Press.

21. Golovnja R. V., Misharina T. A. (1980), Termodinamicheskaja traktovka poljarnosti i selektivnosti sorbentov v gazovoj hromatografii, Uspehi himii, 49(1), pp. 171-191.

22. Sakodynskij K.I. (1993), Analiticheskaja hromatografija, Moscow.

23. Ajvazov B. V. (1983), Vvedenie v hromatografiju: Uchebn. posobie dlja him. spec. vuzov, Moscow.

24. Niessen W. (2001), Current Practice of Gas Chromatography - Mass Spectrometry, Marcel Dekker.

25. Vinarskij V.A. (2003), Hromatografija, Available at: http://anubis.bsu.by/publications/elresources/Chemistry/vinarski.pdf

26. Nolvachai, Yada, Chadin Kulsing, and Philip J. (2017), Marriott. "Multidimensional gas chromatography in food analysis, TrAC Trends in Analytical Chemistry, 96, pp. 124-137.

27. Golbert K. A. (1990), Vedenie v gazovuju hromatografiju, Moscow.

28. Smith I. (2013), Chromatography, Elsevier.

29. Rohrschneider L. (1969), A method for the characterization of stationary liquids in gas chromatography. II. Calculation of retention ratios, Journal of chromatography, 39(4), pp. 383397.

30. McReynolds, W. O. (1966), Gas chromatographie retention data, Preston technical abstracts, 312, pp. 234-241

31. Kaplan I. G. (2012), Mezhmolekuljarnye vzaimodejstvija. Fizicheskaja interpretacija, komp'juternye raschety i model'nye potencial, Moscow.

32. Colin F. (2020), Evaluation of the Solvation Parameter Model as a Quantitative StructureRetention Relationship Model for Gas and Liquid Chromatography, Journal of Chromatography, A, p. 461.

33. Jianwu W. (2018), Qualitative analysis of flavors and fragrances added to tea by using GC-MS, Journal of separation science, 41(3), pp. 648-656.

34. Berenstein N. (2018), Designing flavors for mass consumption, The Senses and Society, 13(1), pp. 19-40.

35. Frolova N., E. (2014), Development of techniques for capillary chromatography of terpene hydrocarbons and oxygenated of essential oils, Eastern-European Journal of Enterprise Technologies, 5(11), pp. 57-64.

36. Frolova N. (2012), Preparatyvne vydilennia indyvidualnykh aromatychnykh komponentiv efirnoii olii kmynu, Ukrainian Food Journal, 1, pp. 62-65.

37. Frolova N. E. (2016), Kompiuterna prohrama rozrakhunku hazokhromatychnykh parametriv utrymuvannia komponentiv efirnykh olii, Visnyk Khmelnytskoho natsionalnoho universytetu: Tekhnichni nauky, 6, pp. 133-137.

38. Ewell R.H. (1944), Azeotropic distillation, Ind. Eng. Chem, 36(10), pp. 871-875. 